\title{
ROMSPath v1.0: Offline Particle Tracking for the Regional Ocean Modeling System (ROMS).
}

5 Elias Hunter ${ }^{1}$, Heidi L. Fuchs ${ }^{1}$, John L. Wilkin ${ }^{1}$, Gregory P. Gerbi ${ }^{2}$, Robert Chant ${ }^{1}$, and Jessica C. Garwood $^{1}$

${ }^{1}$ Department of Marine and Coastal Sciences, Rutgers, The State University of New Jersey, New Brunswick, New Jersey

${ }^{2}$ School of Marine Sciences, University of Maine, Orono, Maine

10 Correspondence to: Elias J. Hunter(hunter@marine.rutgers.edu)

Abstract. Offline particle tracking (OPT) is a widely used tool for the analysis of data in oceanographic research. Given the output of a hydrodynamic model, OPT can provide answers to a wide variety of research questions involving fluid kinematics, zooplankton transport, the dispersion of pollutants, and the fate of chemical tracers, among others. In this paper, we introduce ROMSPath, an OPT model designed to complement the Regional Ocean Modelling System (ROMS). Based on the Lagrangian

15 TRANSport (LTRANS) model (North et al., 2008), ROMSPath is written in Fortran 90 and provides advancements in functionality and efficiency compared to LTRANS. First, ROMSPath now calculates particle trajectories using the ROMS native grid, which provides advantages in interpolation, masking, and boundary interaction, while improving accuracy. Second, ROMSPath enables simulated particles to pass between nested ROMS grids, which are an increasingly popular tool to simulate the ocean over multiple scales. Third, the ROMSPath vertical turbulence module enables the turbulent (diffusion) time step

20 and advection time step to be specified separately, adding flexibility and improving computational efficiency. Lastly, ROMSPath includes new infrastructure enabling input of auxiliary parameters for added functionality. In particular, Stokes drift can be input and added to particle advection. Here we describe the details of these updates and improvements.

\section{Introduction}

Investigation of oceanic processes using particle tracking models is widespread, and applications span several disciplines, including hydrodynamics (Beron-Vera \& LaCasce, 2016; Chu et al., 2004), biological/chemical processes (North et al., 2008), pollution transport (Liubartseva, Coppini, Lecci, \& Clementi, 2018) and turbulence (Yeung, 2002), to name a few. Particle tracking provides insight into ocean circulation from turbulent to global scales (van Sebille et al., 2018), the fate/dispersal of larvae and chemical tracers (Banas, McDonald, \& Armstrong, 2009; North et al., 2008), and the complex kinematics of the ocean (Rypina, Pratt, Pullen, Levin, \& Gordon, 2010; Shadden, Lekien, \& Marsden, 2005). Operationally, particle track forecasting informs search and rescue and oil spill mitigation (Beegle-Krause, 2001). Despite these widespread uses, particle 
tracking models have shortcomings that limit their uses; here we describe improvements to one such model that make it more widely applicable.

Particle tracking models use a velocity field to estimate the trajectories of simulated particles through space and time. For the purpose of this paper, we limit our discussion to 4-dimensional hydrodynamic model output (three spatial dimensions plus time), although trajectories can be calculated from observations and on a variety of dimensions, with or without time. Many hydrodynamic models have the ability to calculate particle trajectories at model run time. Here we discuss the generation of particle trajectories using the saved output of a previously run model, referred to as offline particle tracking (OPT). Examples of existing OPT models are TRACMASS (Döös, Jönsson, \& Kjellsson, 2017), PARCELS (Lange \& van Sebille, 2017), OpenDrift (Dagestad, Röhrs, Breivik, \& Ådlandsvik, 2018), and OceanTracker (Vennell, Scheel, Weppe, Knight, \& Smeaton, 2021) that calculate particle trajectories for a variety of applications. Often, OPT models are designed to simulate forcing and behaviour beyond the scope of the hydrodynamic model, such as random motion associated with subgrid scale processes, larval swimming speed, windage forces on disabled vessels, or sediment settling velocity. Thus, OPT models offer flexibility and efficiency to address scientific questions that may not have been at the forefront when the hydrodynamic model was run, or that demand experimentation with conditions or parameters that are independent of the ocean model itself. It is not uncommon for users to modify OPT models to add novel processes for individual studies. Here, we describe alterations and additions to an existing OPT code, the Lagrangian TRANSport model (LTRANS), to add specific larval behaviour and improve the model's efficiency, accuracy and generality.

50 LTRANS is a well-documented tool widely used in the study of larval transport processes (North et al., 2008). In order to address the scientific objectives of our research project, we started with the LTRANS framework and added support for nested hydrodynamic model grids, Stokes drift velocities which are absent from the hydrodynamic model, novel larval behaviour dependent on turbulent and wave motions, and a larval growth model. In addition to these features, we modified the LTRANS kernel to improve the accuracy of the computed particle trajectories. This paper describes these updates and upgrades focusing on hydrodynamics and user options. Details of new larval behaviour algorithms are described by Garwood et al. (2021). Our changes to LTRANS' internal numerics were substantial enough that we refer to this new model as ROMSPath, to clearly distinguish it from LTRANS.

ROMSPath is written specifically for output from the Regional Ocean Modelling system (ROMS) (Shchepetkin \& 60 McWilliams, 2005) managed via the myroms.org user portal. In principle, however, it could be used with output from any model using a curvilinear Arakawa C grid and terrain-following vertical coordinates with minimal alteration. The algorithm and updates to ROMSPath are described in section 2. To illustrate ROMSpath features, we use hydrodynamic model output generated for the larval transport study mentioned above. A set of example configurations are described in section 3, and results of several tests are shown in section 4 . A brief discussion is presented in section 5. 


\section{ROMSPath description}

ROMSPath is written in Fortran 90, a language widely used in hydrodynamic modelling, using a modular design to ease the addition of new features by other users. The core function of ROMSPath is the advection of passive particles through space and time using 4-D hydrodynamic model output from ROMS and, optionally, Stokes drift computed from a wave model.

70 ROMSPath solves the system of ordinary differential equations (ODE) that describe the particle position vector $\overrightarrow{\boldsymbol{X}}$

$\overrightarrow{\boldsymbol{X}}(t+\Delta t)=\overrightarrow{\boldsymbol{X}}(t)+\Delta \overrightarrow{\boldsymbol{X}}_{\text {hydro }}+\Delta \overrightarrow{\boldsymbol{X}}_{\text {vturb }}+\Delta \overrightarrow{\boldsymbol{X}}_{\text {hturb }}+\Delta \overrightarrow{\boldsymbol{X}}_{\text {behavior }}$

where $t$ is time and $\Delta t$ is the duration of the discrete time step. The initial position of each particle is $\overrightarrow{\boldsymbol{X}}_{o}=\overrightarrow{\boldsymbol{X}}\left(t=t_{o}\right)$ at time

$75 t_{o} . \Delta \overrightarrow{\boldsymbol{X}}_{\text {hydro }}$ is the particle displacement associated with the 4-D velocity field output by ROMS, calculated using a fourthorder Runge-Kutta ODE solver. $\Delta \overrightarrow{\boldsymbol{X}}_{v t u r b}$ is a vertical random displacement calculated as a modified random walk (J. R. Hunter, Craig, \& Phillips, 1993; Visser, 1997) using the vertical turbulent diffusivity calculated by the ROMS turbulence closure scheme and saved as part of the time-varying model output. $\Delta \overrightarrow{\boldsymbol{X}}_{\text {hturb }}$ is a horizontal random displacement associated with horizontal dispersion, calculated as a random walk using a constant horizontal diffusion coefficient (J. R. Hunter et al., 1993;

80 Visser, 1997) set by the user. $\Delta \overrightarrow{\boldsymbol{X}}_{\text {behavior }}$ is the displacement associated with non-hydrodynamic motions such as swimming or sinking, of each particle.

\subsection{Coordinate System and Interpolation}

85 Integration of Eq. (1) requires interpolation of hydrodynamic model information to the time-varying location of each particle at each step. Interpolation carries a computational cost and can be facilitated by a well-chosen coordinate system. LTRANS structures this process by transforming the ROMS curvilinear grid to an intermediate Cartesian coordinate system defined using great circle distances to convert from geographic spherical coordinates. Necessary hydrodynamic parameters are interpolated to particle locations on this grid, then the velocity components defined in the local ROMS curvilinear grid directions are rotated to match the intermediate coordinate system (east-north coordinates). Integration of Eq. (1) then proceeds on the intermediate Cartesian grid, after which particle locations are interpolated to geographic coordinates.

This intermediate interpolation and its sensitivity to the choice of reference latitude/longitude is a source of error in solving Eq. (1) (see sections 3 and 4), and this interpolation is eliminated in ROMSPath by instead operating entirely in the ROMS

95 native curvilinear coordinate system. These coordinates are illustrated in Fig. 1, wherein horizontal position is denoted in fractional non-dimensional coordinates $(\xi, \eta)$ (Haidvogel et al., 2000) and the orthogonal curvilinear coordinate transformation 
https://doi.org/10.5194/gmd-2021-400

Preprint. Discussion started: 20 December 2021

(c) Author(s) 2021. CC BY 4.0 License.

(c) (i)

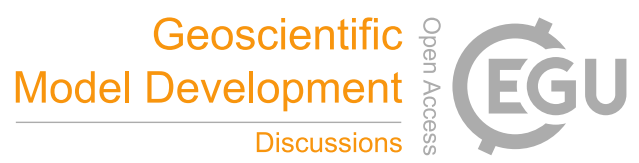

is described by local Lamé metrics that represent the arc length associated with unit increments in $\xi$ and $\eta$. This approach has two benefits: 1) the grid cell in which a particle is located is known simply by rounding its fractional $\xi, \eta$ position, making it trivial to identify interactions with open boundaries and land masks, and 2) the unit cell size greatly simplifies bi-linear interpolation of the state variables. The kinematic boundary condition of no flow across the discrete coastline is also enforced, reducing the number of particles that run aground. Using the native coordinates in this way mirrors the online particle tracking algorithm within ROMS.

The horizontal bi-linear interpolation is immediately followed by the vertical interpolation of hydrodynamic parameters at 105 each time step. The vertical interpolation for most parameters is linear. The exception is the vertical tracer (salinity/temperature) diffusivity, which is input to the vertical turbulence module. This diffusivity is interpolated using a cubic spline. 
https://doi.org/10.5194/gmd-2021-400

Preprint. Discussion started: 20 December 2021

(c) Author(s) 2021. CC BY 4.0 License.

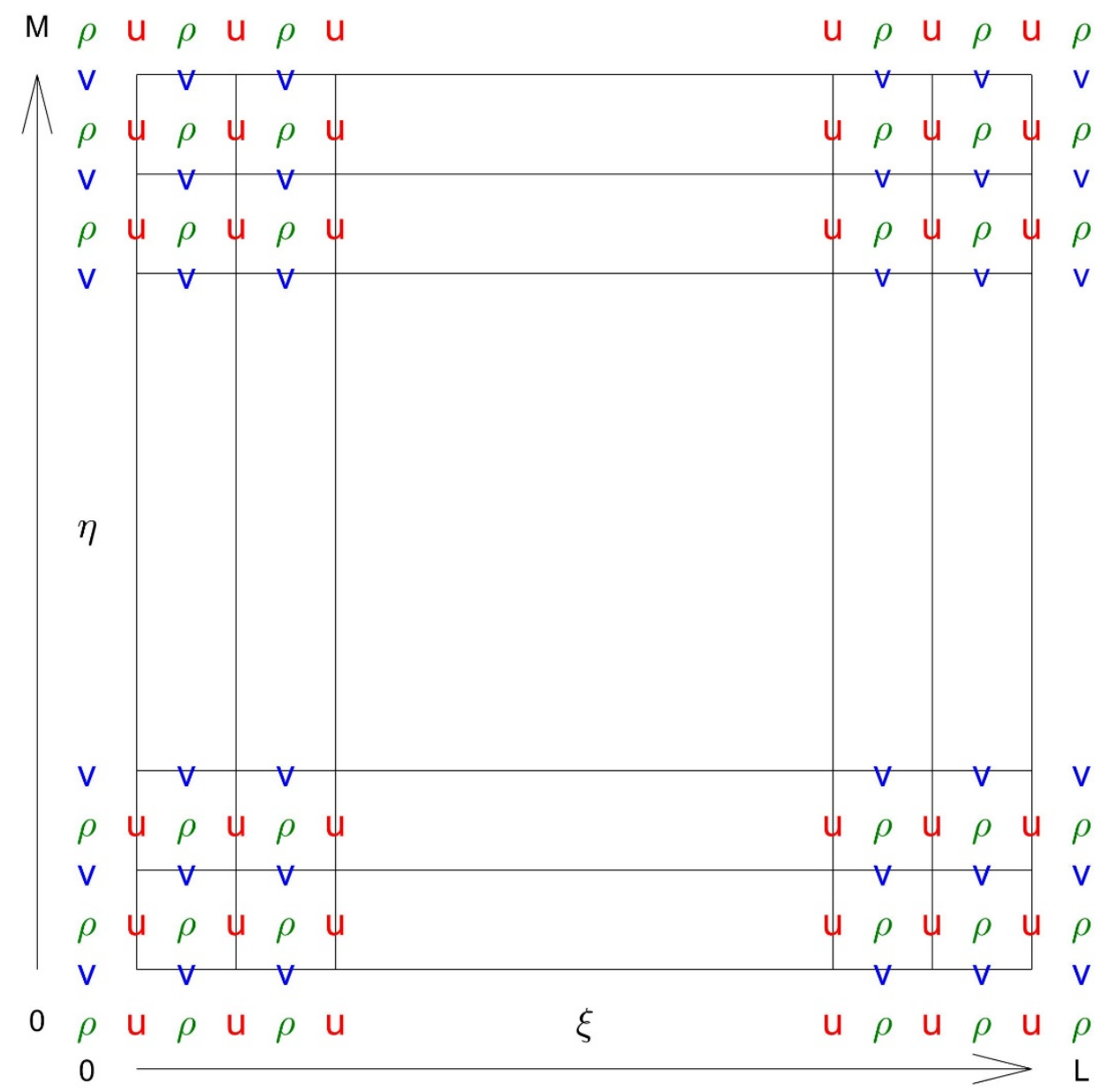

110 Figure 1. An example of the Arakawa C-grid ROMS grid used for internal computation, in $\xi$, $\eta$ coordinates. The $\rho$ points are the grid locations of tracers (salinity/temperature). The $u$ and $v$ grid locations are for velocities in the $\xi$ and $\eta$ directions respectively. $L$ is the dimension of the grid in the $\xi$ direction and $M$ is the dimension of the grid in the $\eta$ direction. For reference to the model domain in our examples, in Fig. 1 the $\xi$ direction points to the northeast and the $\eta$ direction points to the northwest. 
https://doi.org/10.5194/gmd-2021-400

Preprint. Discussion started: 20 December 2021

(c) Author(s) 2021. CC BY 4.0 License.

(c) (i)

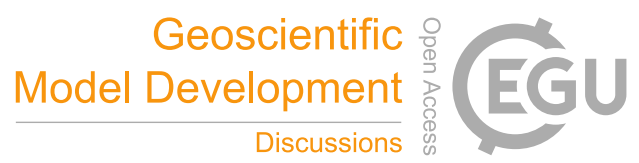

\subsection{Nesting}

115 Coastal ocean hydrodynamic modelling sometimes demand that a range of scales be resolved across the region of interest to properly simulate the physical processes of importance. For example, an estuary model might need finer resolution than a model of the adjacent coastal region. While high resolution might be used throughout the domain, the computational cost can be problematic or even prohibitive. Ocean modellers address this problem in various ways, including the use of unstructured grids with resolution adapted to subregions, or nested model grids. ROMS includes the facility for a nested grid approach,

120 where a fine resolution grid covering a small domains (a "refinement grid") is nested inside a larger domain, coarser resolution grid, with optionally one-way (i.e., downscaling) or two-way (i.e., coupling) exchange of information between the grids. The footprints of the grids used in our study and described in Section 3 are shown in Fig. 2. 
https://doi.org/10.5194/gmd-2021-400

Preprint. Discussion started: 20 December 2021

(c) Author(s) 2021. CC BY 4.0 License.

\section{Geoscientific o

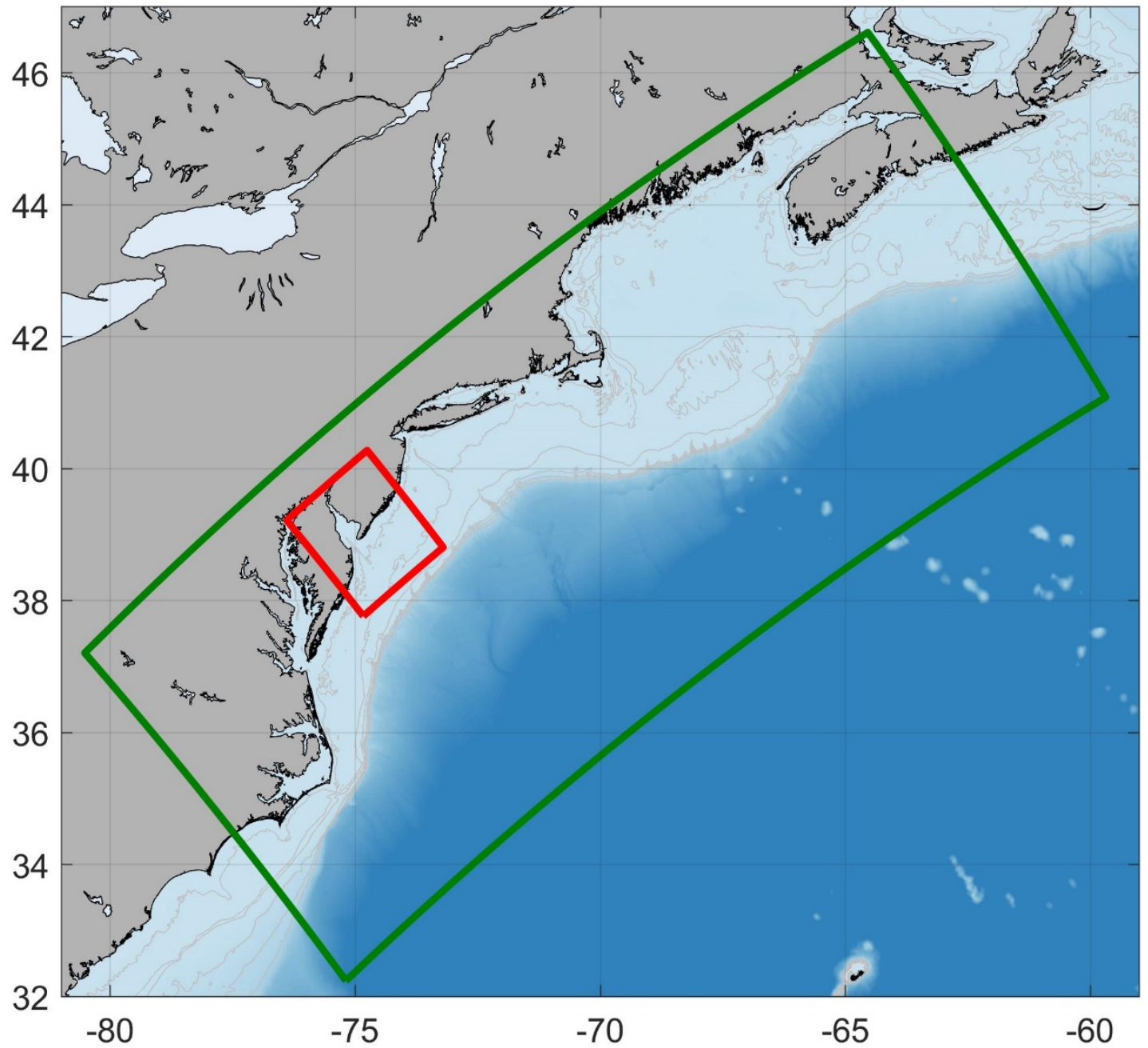

Figure 2. Map of the test domains. Green outlines the Doppio grid with $\sim 7 \mathrm{~km}$ resolution. Red outlines the SnailDel domain with resolution of $\sim 1 \mathbf{k m}$. 
LTRANS can, in principle, use nested model output for particle tracking but presently lacks the infrastructure to simultaneously process ROMS outputs from multiple grids in a nested grid hierarchy and seamlessly follow particles as they traverse the boundaries between parent and refinement grids. ROMSPath includes this functionality and draws hydrodynamic information from the most appropriate grid in the simulation. A representation of the grid decision tree is shown in Fig. 3 . If the particle is inside a refinement grid, then ROMSPath uses velocities from that grid. Otherwise, it uses velocities from the parent grid. The grid that a particle is associated with is checked at every time step, starting with the highest resolution (smallest footprint) refinement grid. If the particle crosses a grid boundary its current grid is updated, its location is calculated in the new grid coordinate system, and advection continues on the new grid. Although the example shown here uses only one refinement grid, ROMSPath is capable of handling any number of refinement grids.

Open boundaries and coasts are handled in ROMSPath as they are in LTRANS. When a particle contacts an open boundary of the outermost domain, it is considered to have left the domain and its position is no longer tracked. When a particle encounters a closed boundary (surface, bottom, or coastline), it is reflected back into the domain by a distance equal to the distance it would have travelled past that closed boundary.

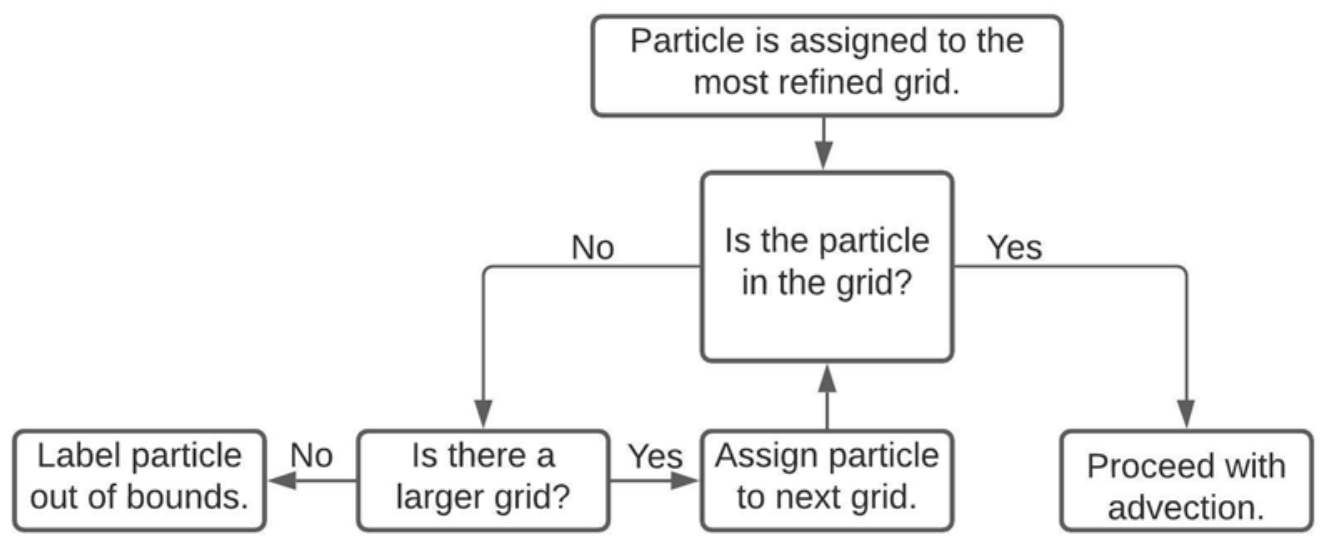

Figure 3. Flow diagram of the grid assignment process. At each time step particles are assigned to the most refined grid first. If the particle is determined to be within that grid domain, advection continues. If the particle is outside the domain, the next refined grid is checked. If the particle is not found to be within the domain of any grid, advection for that particle stops.

\subsection{Vertical turbulent transport parameterization with split time stepping.}

The vertical component of velocity in the advection term in Eq. (1) implicitly averages over the time scales of displacements associated with sub-grid scale vertical turbulence unresolved by the hydrodynamic model. These motions are typically introduced in OTP models through the use of a "random walk" model applied to an ensemble of particles to represent the net 

ROMSPath requires that vertical tracer diffusivity be included in the ROMS output.

ROMSPath uses the same conceptual approach as LTRANS for implementing the vertical random walk, but it includes some improvements. The vertical random walk algorithm is that of (J. R. Hunter et al., 1993; Visser, 1997), which is designed for

155 systems with spatially varying diffusivities. Specifically, for a simple random walk model, numerical imprecision inevitably leads to a clustering of particles in regions of low diffusivity (see section 4.2). The modified vertical random walk, developed from consideration of the moments of the particle distribution, prevents such unrealistic particle clustering. The random walk is implemented in ROMSPath as:

$\Delta z_{t u r b}=\frac{\delta K}{\delta z} \Delta t+R\left\{\frac{2}{r} K\left[z_{t}+\frac{\delta K}{2 \delta z} \Delta t\right]\right\}^{1 / 2}$

where $z$ is the particle's vertical location and $K$ is the diffusivity reported by ROMS. $R$ represents a random process with zero mean and a standard deviation equal to $r$. The vertical gradient of the diffusivity is extracted from the cubic spline interpolation of the diffusivity profile. This approach is common in other OPT models (Lett et al., 2008; van Sebille et al., 2018; Xue, Incze, Xu, Wolff, \& Pettigrew, 2008).

The algorithm described above reduces the clustering problem but requires a relatively short time step which can be computationally costly. In ROMSpath, we decouple the time steps for the random walk and advection, enabling the vertical diffusion model to run with a smaller time step than the advection model, thus reducing the computational cost without sacrificing a realist distribution of particles due to vertical random processes. During the process of updating LTRANS to ROMSPath, we also noted an error in the implementation of the vertical random walk model, which resulted in an increase in unrealistic clustering when running LTRANS(see section 3.3.2). Specifically, a sign error in the last term of Eq. (2) as it is implemented in the latest version of LTRANS led to increased particle clustering (see section 4.2). This error is corrected in ROMSPath.

\subsection{Wetting and Drying}

ROMSPath adds the capability to correctly handle particle transport when the ROMS option for wetting and drying (Warner, Defne, Haas, \& Arango, 2013) is activated. This option is useful in shallow, tidal, estuarine environments where mudflats can be above or below the waterline depending on the phase of the tide. Wetting and drying in ROMS is implemented using a time-varying land mask to identify areas that transition from "wet" to "dry" when the depth of water above the seabed falls below a user defined critical value. If ROMS has been run with wetting and drying (and the appropriate user flags are set) the time-varying mask is saved in the output. ROMSPath uses this mask to establish boundaries to advection that prevent a particle 
from entering a "dry" cell, which would lead to an ungraceful failure during execution. A particle encountering a "dry" cell will behave as if the cell were a land point, reflecting back into the wet cell. Particles occupying a cell that becomes dry will not move until the cell becomes wet again. Reading the wet-dry mask from the ROMS output at every time step increases the I/O load slightly, but the increase in run time is minimal.

\subsection{Stokes Drift}

Stokes drift can contribute to particle transport, particularly in near-shore, shallow-water environments (Feng et al., 2011; Monismith \& Fong, 2004; Röhrs et al., 2012). However, few OPT models include a Stokes drift term in the advection scheme, presumably because the necessary wave information is not readily available. Some models, such as OpenDrift, allow for parameterizing Stokes drift based on the wind velocity. ROMS includes options to use wave information provided as external forcing data in the calculation of wave-current interaction effects on bottom drag and turbulent kinetic energy input at the sea surface due to wave breaking. In such configurations, the wave information is exported to the output and could be available to ROMSpath. In the event these options are not active, as is the case here, including Stokes drift in ROMSPath requires an additional input that contains Stokes drift velocities stored on the ROMS grid. These velocities are calculated separately using output from a wave model, and read in at the same time as the ROMS model output to calculate a Lagrangian velocity field as

$\overrightarrow{\mathbf{V}}_{\text {mean }}(\overrightarrow{\boldsymbol{x}}, t)=\overrightarrow{\mathbf{V}}_{\text {hydro }}(\overrightarrow{\boldsymbol{x}}, t)+\overrightarrow{\mathbf{V}}_{\text {stokes }}(\overrightarrow{\boldsymbol{x}}, t)$

200 where $\overrightarrow{\mathbf{V}}_{\text {mean }}$ is the 4-D velocity field used by ROMSPath to determine $\Delta \overrightarrow{\mathbf{X}}_{\text {mean }}$ in (1) for advection, $\overrightarrow{\mathbf{V}}_{\text {hydro }}$ are velocities from the ROMS hydrodynamic files, and $\overrightarrow{\mathbf{V}}_{\text {stokes }}$ are velocities from the Stokes drift files.

\subsection{Behavioural inputs.}

205 LTRANS allows particle behaviours to vary as functions of ROMS hydrodynamic variables temperature or salinity. ROMSPath was developed for studies in which larval swimming behaviour can also depend on flow vorticity and acceleration. These added behavioural inputs are incorporated in much the same way as Stokes drift, by reading files prepared offline with parameters stored on the ROMS grid, in both space and time. These parameters are interpolated to instantaneous particle positions and then used in ROMSPath to compute behavioural velocity, just as LTRANS does for temperature and salinity.

210 This framework can be easily modified to allow other inputs for behavioural cues (e.g. irradiance). ROMSPath retains the LTRANS option for a simple vertical swimming behaviour, where a constant vertical swimming velocity is specified and added to the particle's velocity vector $\overrightarrow{\mathbf{v}}$. 


\section{Test cases}

\subsection{ROMS Model setup}

We formulated test cases using 4-D hydrodynamic output from an existing implementation of ROMS in the northeast United States known as “Doppio” (Levin, Arango, Laughlin, Wilkin, \& Moore, 2019; López, Wilkin, \& Levin, 2020; Wilkin et al., 2018). The domain (shown in green in Fig. 2) has a horizontal resolution of 7 km and extends from south of Cape Hatteras to Nova Scotia.

Forcing and boundary conditions are described by López et al. (2020). In short, meteorological forcing is provided by the North American Regional Reanalysis (NARR) (Mesinger et al., 2006) and the North American Mesoscale forecast model (NAM) (Janjic, 2005). River runoff is obtained from the United States Geological Survey (USGS) (http://waterdata.usgs.gov) and the Water Survey of Canada (WSC) (https://wateroffice.ec.gc.ca/) and introduced as point sources of freshwater along the coastline. Open boundary conditions are daily mean data from the Mercator Océan system)(Drévillon et al., 2014; Lellouche et al., 2018) with tidal constituents of sea-level and velocity added from the Oregon State University Tidal Predication Software (OTPS) (Egbert \& Erofeeva, 2002). Vertical mixing is parameterized using the generic length scale parameterization of Umlauf and Burchard (2003), configured to the closure described by Mellor and Yamada (1982). Horizontal mixing is parameterized as harmonic horizontal mixing along sigma surfaces for momentum, and geopotential surfaces for tracers.

The Doppio model setup in this study differs from López et al. (2020) in two ways. First, we took advantage of a previously developed data-assimilative Doppio implementation (Levin et al., 2019) by nudging temperature and salinity to the dataassimilative result with a 3-day time scale in waters with bottom depth greater than 10 meters. This nudging constrains the density field and mesoscale geostrophic velocity to remain close to the data assimilative analysis without the added cost of rerunning the data assimilation itself.

Second, the study that motivated ROMSPath investigated particle exchange between Delaware Bay and the adjacent shelf, so inside the Doppio domain we nested a fine resolution grid, named "SnailDel”. SnailDel (shown in red in Fig. 2) is a sevenfold refinement of the Doppio grid and has a horizontal resolution of $\sim 1 \mathrm{~km}$. We implement a coupled (two-way) nesting paradigm where the "parent" grid (Doppio) provides open boundary conditions to the "refinement" grid (SnailDel). Information feeds back to the Doppio domain by replacing the state variables at Doppio grid points within the SnailDel domain with spatially averaged SnailDel state variables. Meteorological forcing is the same as Doppio. River forcing is also from USGS, although more river sources are in the SnailDel domain than the equivalent domain in Doppio.

245 For the examples shown here, hydrodynamic output was saved every 12 simulated minutes for both model grids to meet specific scientific goals, such as resolving tidal variation in estuarine turbulence. 


\subsection{Wave model}

Wave conditions were simulated for three uses: 1) to estimate whitecapping energy inputs to the ROMS turbulence model, 2) to determine Stoke drift for particle transport, and 3) to determine accelerations felt by particles for behavioural responses. We modelled waves using Simulating WAves Nearshore (SWAN), a third generation spectral wave model (Booij, Ris, \& Holthuijsen, 1999; Ris, Holthuijsen, \& Booij, 1999). SWAN was run independently from the Doppio/SnailDel nested hydrodynamic run, and ROMS and SWAN were not directly coupled. The SWAN model grids for SnailDel and Doppio are collocated with the ROMS grids and use the same bathymetry. The SWAN grids were 1-way nested, with the SnailDel grid receiving wave open boundary conditions from the SWAN Doppio grid, while Doppio used wave open boundary conditions from NOAA Wavewatch III (Tolman, 2002). Meteorological forcing for the SWAN model runs are the same as for the ROMS hydrodynamic runs, and output is saved at the same frequency.

The turbulence surface boundary condition for ROMS was determined using methods similar to those described in Gerbi, Kastner, and Brett (2015) and Thomson et al. (2016). Stokes drift was calculated from the directional wave spectrum following Phillips (1966), equation 3.3.5, and saved in separate files for use in ROMSPath.

\subsection{Configurations}

One motivation for the development of ROMSPath was to enable the use of nested-grid output from ROMS, which led to a number of useful changes to the underlying code (ROMS grid coordinates, turbulence, wetting and drying). We performed 11 simulations to evaluate many of these changes. The configurations for each of these tests are described here, and summarized in Table 1. Results are described in section 4.

\begin{tabular}{|c|c|c|c|c|c|c|c|c|c|}
\hline Case Name & Model & Nested & $\begin{array}{c}\text { Vertical } \\
\text { Turbulence }\end{array}$ & $\begin{array}{l}\text { Horizontal } \\
\text { Turbulence }\end{array}$ & $\begin{array}{c}\text { Stokes } \\
\text { drift }\end{array}$ & $\begin{array}{c}\text { Vertical } \\
\text { Initialization }\end{array}$ & $\begin{array}{c}\text { Horizontal } \\
\text { Initialization }\end{array}$ & $\begin{array}{c}\text { \# of } \\
\text { particl } \\
\text { es }\end{array}$ & Comments \\
\hline LTRANS OTP & LTRANS & No & No & No & No & Point at $-1 \mathrm{~m}$ & $15 \mathrm{~km}$ filled circle & 32000 & Ref.: 32.0N, 81.0W, 90 day run \\
\hline ROMSPath OTP & ROMSPath & No & No & No & No & Point at $-1 \mathrm{~m}$ & $15 \mathrm{~km}$ filled circle & 32000 & $\eta, \xi$ coord., 90 day run \\
\hline ROMS Floats & ROMS & No & No & No & No & Point at $-1 \mathrm{~m}$ & $15 \mathrm{~km}$ filled circle & 32000 & $\begin{array}{l}\text { Run online using the Doppio gric } \\
\text { with ROMS Floats enabled. }\end{array}$ \\
\hline Vert. LTRANS & LTRANS & No & Yes & No & No & Line & Point & 3285 & $\mathrm{dt}=60 \mathrm{~s}, 2$ day run \\
\hline Vert. ROMSPath & ROMSPath & No & Yes & No & No & Line & Point & 3285 & $\mathrm{dt}=60 \mathrm{~s}, 2$ day run \\
\hline No Nest/No Turb. & ROMSPath & No & No & No & No & Point at $-1 \mathrm{~m}$ & $45 \mathrm{~km}$ filled circle & 6000 & 30 day run \\
\hline Nest/No Turb. & ROMSPath & Yes & No & No & No & Point at $-1 \mathrm{~m}$ & $45 \mathrm{~km}$ filled circle & 6000 & 30 day run \\
\hline No Nest/Turb. & ROMSPath & No & Yes & Yes & No & Point at $-1 \mathrm{~m}$ & $45 \mathrm{~km}$ filled circle & 6000 & 30 day run \\
\hline Nest/Turb. & ROMSPath & Yes & Yes & Yes & No & Point at $-1 \mathrm{~m}$ & $45 \mathrm{~km}$ filled circle & 6000 & 30 day run \\
\hline NoStokes & ROMSPath & Yes & No & No & No & Point at $-1 \mathrm{~m}$ & $45 \mathrm{~km}$ filled circle & 6000 & 30 day run \\
\hline Stokes & ROMSPath & Yes & No & No & Yes & Point at $-1 \mathrm{~m}$ & $45 \mathrm{~km}$ filled circle & 6000 & 30 day run \\
\hline
\end{tabular}

Table 1: OTP model run configurations 


\subsubsection{Coordinate system}

We evaluated the simulation of particle trajectories on the ROMS native coordinate system using ROMSPath in comparison to the intermediate coordinate system used in LTRANS. The results are compared, further, to the ROMS online particle tracking system referred to here as ROMS floats. ROMS floats particle trajectories are integrated using a $4^{\text {th }}$ order Milne predictor and $4^{\text {th }}$ order Hamming corrector, which is arguably less accurate than ROMSpath, but the calculation is made on every model time step and hence we believe the ROMS floats results represent the most accurate trajectories possible.

We compare three simulations: one via LTRANS which simulates trajectories on an intermediate coordinate system defined using the recommended reference position for the projection (Schlag \& North, 2012), one via ROMSPath which operates on the ROMS native coordinate system (Fig. 1), and one using ROMS floats. All three simulations used the same initial particle positions and omit horizontal and vertical turbulence components. For each case, 32000 particles were randomly distributed throughout a circle $20 \mathrm{~km}$ in diameter near the surface and released. A Doppio simulation (without nesting) that also activated ROMS floats was run for 90 days and hydrodynamic output was saved every 12 minutes. These hydrodynamic outputs were used as input to the LTRANS and ROMSPath simulations.

\subsubsection{Turbulence parameterization}

In order to illustrate the impact of an error in the LTRANS vertical turbulence parameterization, we configured two similar runs for LTRANS and ROMSPath. Both runs are initialized at the same location with 3285 points evenly distributed in the vertical. For this test, LTRANS was coded to include a short time step for turbulence and a longer time step for advection; note that this capability is not native to LTRANS. The turbulent time step is set to 1s and the advection time step was set to 60 295 seconds for both ROMSPath and LTRANS. Both simulations are run for two days.

\subsubsection{Nesting and vertical/horizontal turbulence}

Most numerical models include schemes for vertical and horizontal mixing by unresolved (turbulent) processes, and the magnitude of the mixing coefficients generally vary with the resolution of the grid. Finer grids allow more direct simulation,

300 rather than parameterized simulation, of dynamics and particle trajectories. Because finer grids resolve more processes, the mixing coefficients represent fewer unresolved processes and are therefore smaller. We examined the effect of grid resolution (via the inclusion of nesting) and vertical /horizontal turbulence on particle trajectories using a set of four simulations with the same initial conditions (Table 1). The velocity fields used for particle tracking all came from the same hydrodynamic 
simulations but were used in different ways. All of the hydrodynamic simulations included horizontal mixing (see section 3.1), but in the particle tracking models, horizontal mixing coefficients were not always used. The first case (No Nest/No Turb.) does not use nested output in the OTP model, thus only uses velocities from the Doppio grid (7 km resolution). Further, no horizontal or vertical turbulent parameterizations are supplied during this OTP run. The second case (Nest/No Turb.) uses nested hydrodynamic output; i.e. velocities were from both Doppio and SnailDel (1 km resolution) outputs, but did not include horizontal or vertical turbulent parameterizations. The third (No Nest/Turb.) and fourth (Nest/Turb.) cases are similar to the first two, except that horizontal and vertical mixing were turned on.

In each simulation, 6000 neutrally buoyant particles are initially distributed randomly in a circle (45 km diameter) at 1 meter below the sea surface. The initial condition is located off the central NJ coast, just north of the SnailDel domain.Particles were tracked for 30 days after release, and $100 \%$ of the particles released entered the boundaries of the SnailDel domain at some point during the simulation.

\subsubsection{Stokes drift}

We compare two OTP runs (NoStokes and Stokes cases, Table 1) to test how adding Stokes velocities to the hydrodynamic velocites impacted particle trajectories. The NoStokes case is identical to the Nest/No Turb case from section 3.3.3, while the Stokes case adds Stokes drift from surface gravity waves according to Equation 3.

\section{Results and Discussion}

Here we examine the results of the exploratory simulations described in section 3.3. This examination does not cover all the differences between LTRANS and ROMSPath, but instead focuses on demonstrating the utility of the most important changes.

\subsection{Coordinate system}

Particle trajectories from three simulations, using the LTRANS OTP, the ROMSPath OTP, and ROMS floats (table 1), are compared in Figure 4. The ROMSPath OTP output is always closest to the ROMS floats output; although all results are similar after five days, the discrepancy in LTRANS outputs grows large by 35 days. Compared to LTRANS, the ROMSPath OTP data more accurately reflects the variability of the particles' centre of mass (CM) seen in the ROMS floats data (Fig. 4). Although the CM of LTRANS and ROMS floats data appear to nearly intersect in space, they reach that point at different times. The $\mathrm{CM}$ becomes a less useful metric over time as the distributions become non-Gaussian when particles begin to leave the shelf. In particular, the LTRANS OTP fails to reproduce the off-shelf transport and entrainment of particles into the Gulf Stream 
https://doi.org/10.5194/gmd-2021-400

Preprint. Discussion started: 20 December 2021

(c) Author(s) 2021. CC BY 4.0 License.

(c) (1)

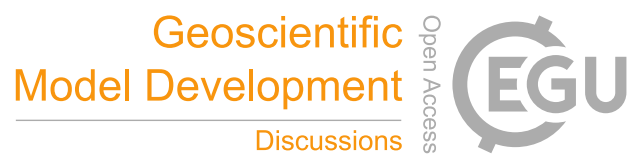

335 seen in the ROMS floats output. This offshelf transport leads to a large dispersal of particles between the Gulf Stream and the Mid-Atlantic shelf break, which is well represented in the ROMSPath OTP output.

We also did simulations to confirm that the LTRANS OTP results get less accurate with an inappropriate choice of reference points for the projection (not shown). Reference points must be chosen with care, but this step is unnecessary with ROMSPath. 
https://doi.org/10.5194/gmd-2021-400

Preprint. Discussion started: 20 December 2021

(c) Author(s) 2021. CC BY 4.0 License.

\section{(c) (1)}

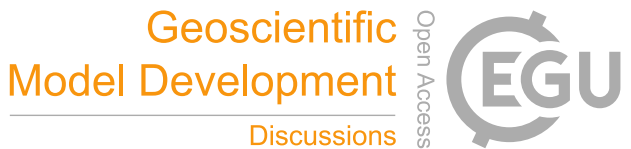
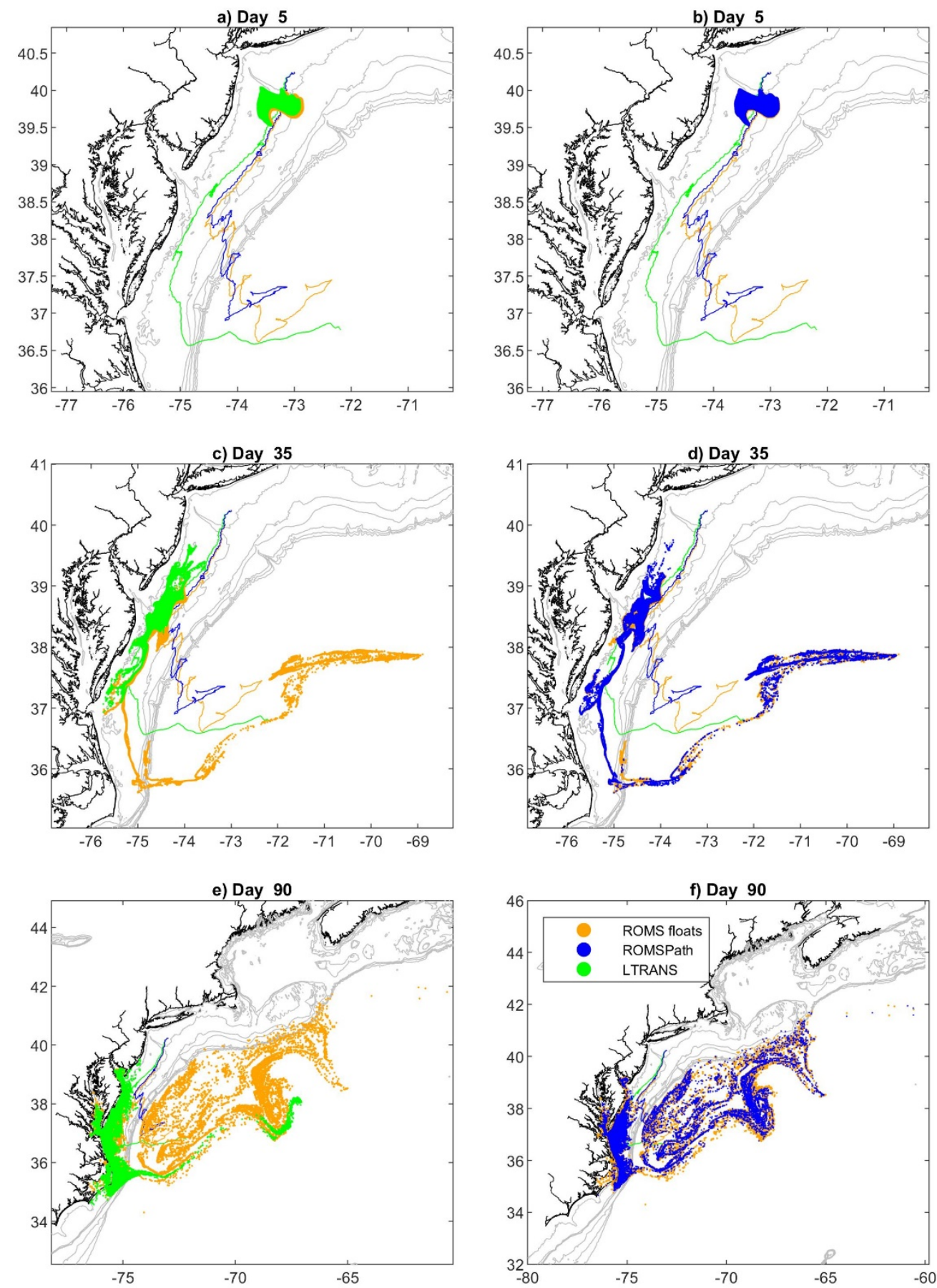
https://doi.org/10.5194/gmd-2021-400

Preprint. Discussion started: 20 December 2021

(c) Author(s) 2021. CC BY 4.0 License.

(c) (1)

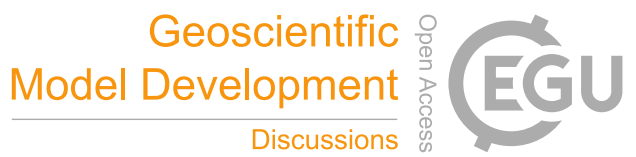

340 Figure 4. Comparison of particle positions in LTRANS OTP (green) and ROMSPath (OTP) (blue) versus ROMS floats (yellow), which represent the most accurate available estimates. For clarity we show separate comparison of LTRANS OTP versus ROMS floats (a,c,e) and ROMSPath vs. ROMS floats (b,d,f). Dots are particle positions at days 5 (a-b), 35 (c-d), and 90 (e-f), and solid lines in all panels are the centres of mass (CM) of particle trajectories over the 90-day simulation. The ROMSPath OTP simulations are more consistent with ROMS floats simulations in dispersion, offshore transport, and trajectory of the CM.

4.2 Vertical interpolation, split time-stepping, and turbulence

Fig. 5 shows a comparison of the vertical distribution for the two cases, Vert. LTRANS, and Vert. ROMSPath (See Table 1).

350 Fig 5a and 5b both show particle density distributions in the vertical over the 2-day period of the simulations. A representative tracer diffusivity profile is overlaid for context. The LTRANS data shows a particle density maximum at the tracer diffusivity minimum. We note from previous work (not shown) that a small enough advective time step in LTRANS ( 1-2s), similar to the scale of the turbulent time step, would mitigate the clustering problem. However, the small time step required has severe consequences for numeric efficiency, particularly for OTP runs with tens of thousands of particles. 
https://doi.org/10.5194/gmd-2021-400

Preprint. Discussion started: 20 December 2021

(c) Author(s) 2021. CC BY 4.0 License.
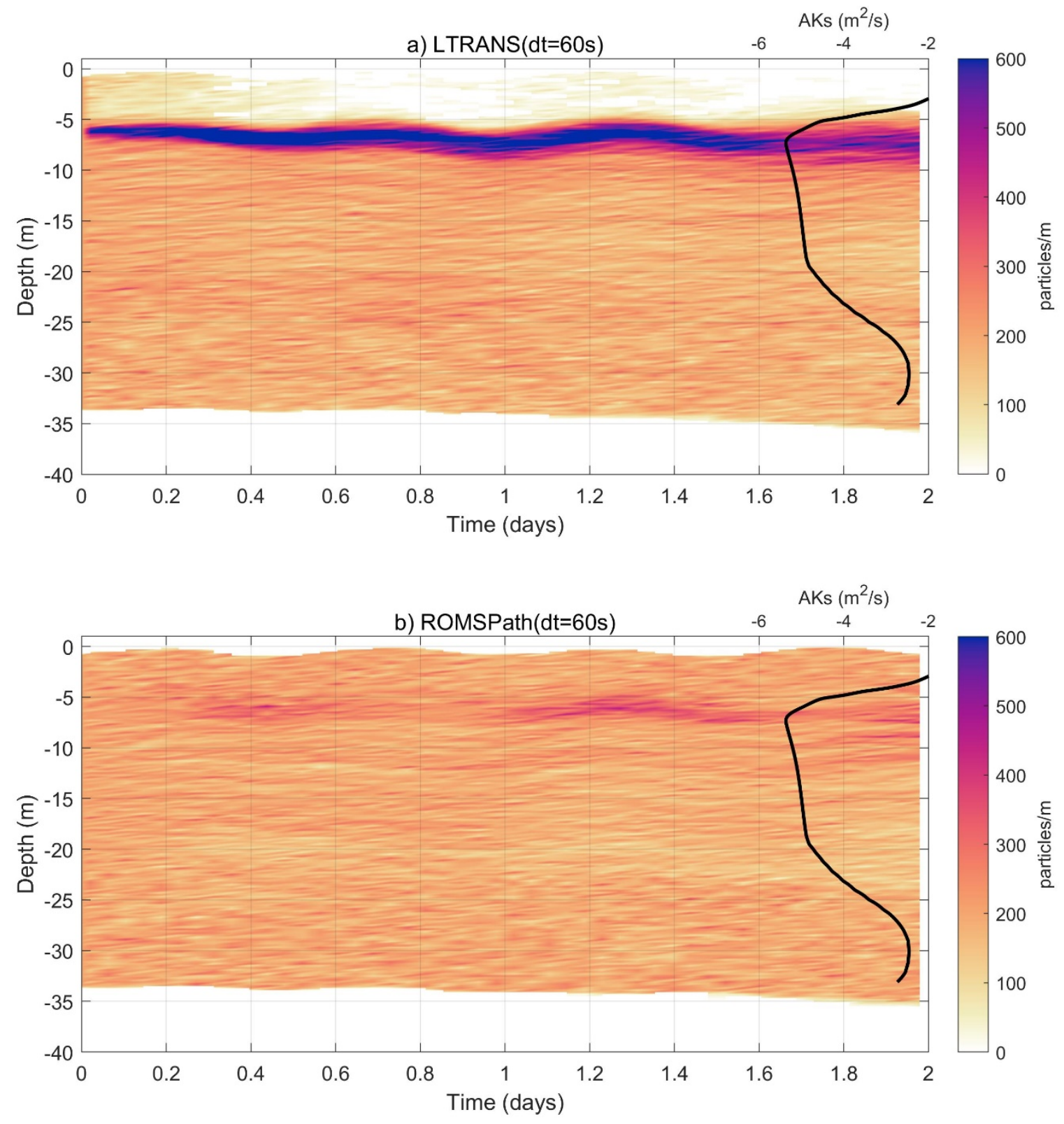

Figure 5. Vertical density of particles over time for a) LTRANS run and b) ROMSPath run. Both runs used a $60 \mathrm{~s}$ time step and were initialized at the same horizontal location and time, with 3285 particles evenly. A representative vertical tracer diffusivity $(\log 10(\mathrm{AKs}))$ is overlayed in black. The LTRANS run has particle clustering at the vertical diffusivity minimum. 
https://doi.org/10.5194/gmd-2021-400

Preprint. Discussion started: 20 December 2021

(c) Author(s) 2021. CC BY 4.0 License.

(c) (i)

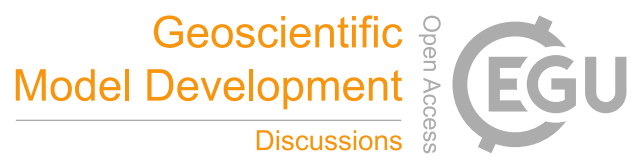

\subsection{Nesting and horizontal mixing}

The nesting and mixing comparisons (Fig. 6) showed that particle dispersion is enhanced by the use of nested grid outputs even when there is no horizontal mixing. Particle trajectories in the No Nest/No Turb case showed fairly coherent structures over time, with some horizontal deformation and little or no vertical dispersion (Fig. 6a, b). The addition of the nested SnailDel grid in Nest/No Turb is revealing. Outside of the SnailDel domain (Fig. 6c, d), the particle transport/dispersion was similar, but inside Snaildel, there was more horizontal dispersion when the nested grid was included (Fig. 6c), enabling some particles to enter Delaware Bay, a potentially significant pathway for material to enter the bay. The vertical distribution of particles in Fig. 6d suggests particles were more likely to enter lower layers. The time-averaged, near-bottom currents at the mouth of Delaware Bay are into the bay (Garvine, 1991), providing a pathway for particles on the shelf to enter the bay. There is no 370 vertical or horizontal mixing parameterized in these two cases, suggesting that smaller scale features, such as fronts, jets, or subduction, resolved by the SnailDel grid allow for enhanced dispersion in the horizontal and vertical relative to the Doppio grid alone.

Particle dispersion is further enhanced with the addition of horizontal and vertical mixing (Figs. 6e-h). When horizontal and 375 vertical mixing are parameterized, we see increased dispersion in all directions for both cases (No Nest/Turb and Nest/Turb). However, dispersion was still more enhanced in the vertical and horizontal when we included nesting in the OTP run (Fig. 6e,f compared to Fig. 6g,h). Thus a combination of including small scale hydrodynamics through nesting and turbulent parameterizations in ROMSPath simulations provides the most dispersion and, for this example, the largest transport of particles into Delaware Bay. 
https://doi.org/10.5194/gmd-2021-400

Preprint. Discussion started: 20 December 2021

(c) Author(s) 2021. CC BY 4.0 License.
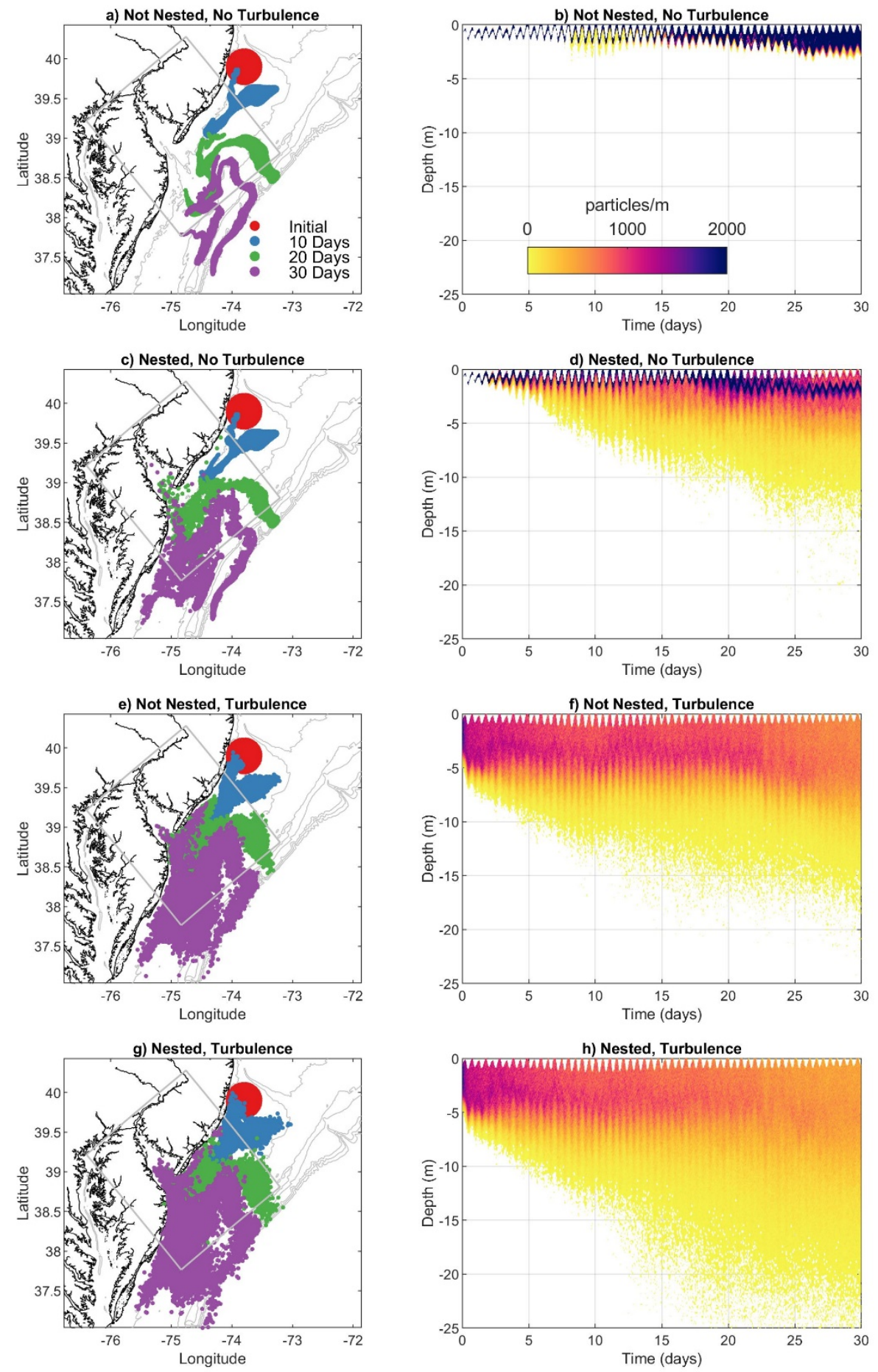
https://doi.org/10.5194/gmd-2021-400

Preprint. Discussion started: 20 December 2021

(c) Author(s) 2021. CC BY 4.0 License.

(c) (i)

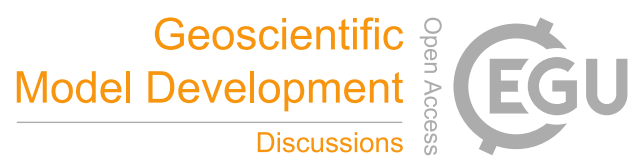

Figure 6. ROMSPath simulations showing particle locations (a,c,e,g) after 10, 20, and 30 days and vertical particle distributions (b,d,f,h over time. Figs. show ROMSPath runs with and without a nested grid and turbulence. The grey box in a,c,e,g is the boundary 385 of the SnaiDel domain.

\subsection{Stokes drift}

390 The addition of Stokes drift also modified trajectories and increased particles' movement onshore. The wave field during thetwo releases was generally swell (6-10 s period) to the north/west (Fig.7c). Given the orientation of the coastline (southwest to northeast), wave swell was onshore during this time period. Results from the runs with and without Stokes drift (Figs. 7a and $7 \mathrm{~b}$ respectively) show a tendency for particles to go farther into Delaware Bay and move closer to the coastline with Stokes drift included. 
https://doi.org/10.5194/gmd-2021-400

Preprint. Discussion started: 20 December 2021

(c) Author(s) 2021. CC BY 4.0 License.

\section{(c) (1)}

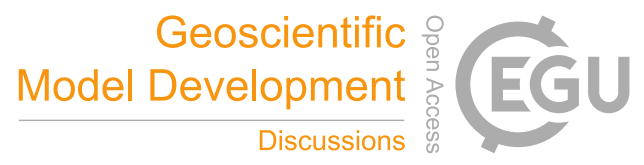

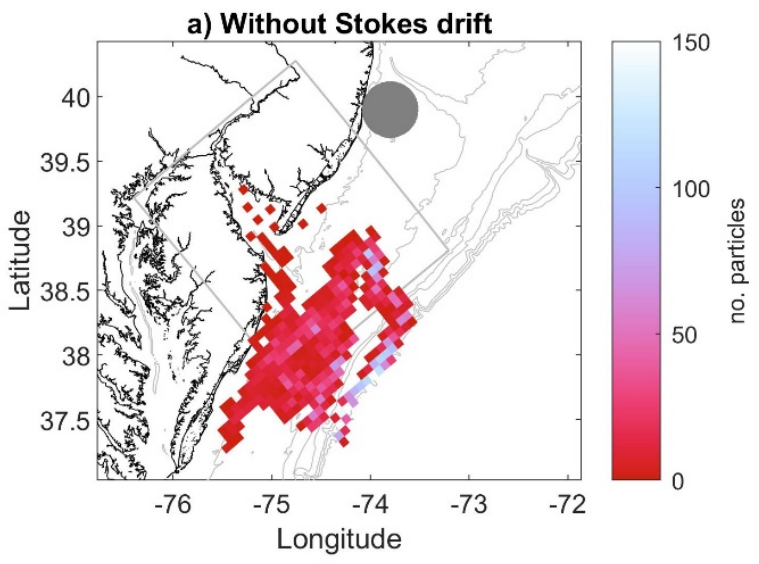

b) With Stokes drift

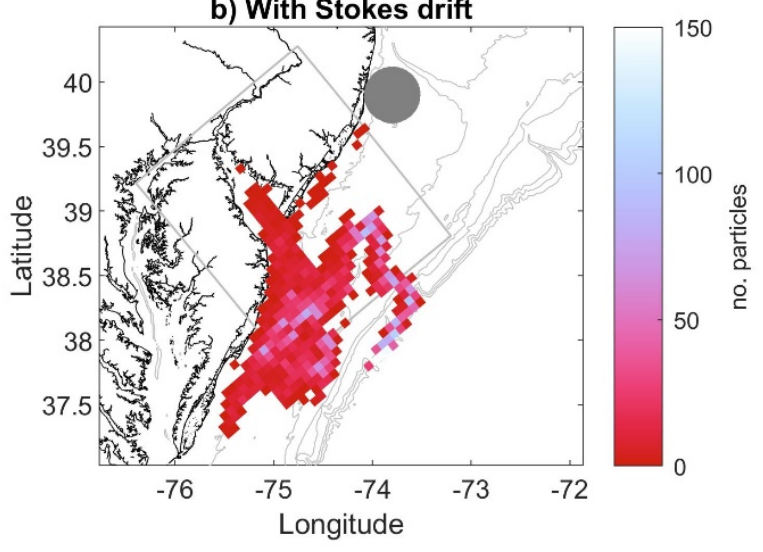

c) Wave Power Spectrum

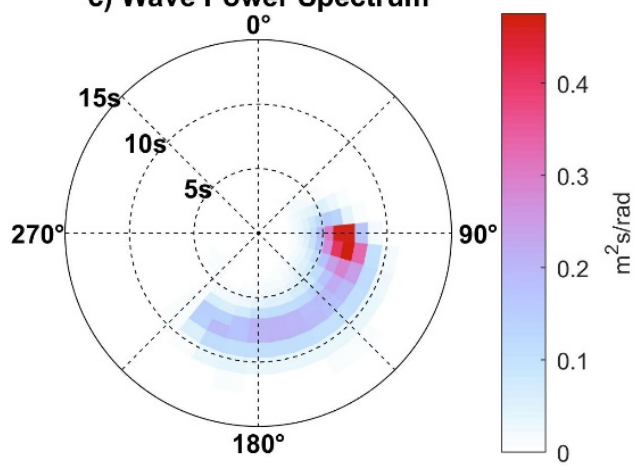


Figure 7. ROMSPath simulations showing particle distributions after 30 days. a) without Stokes drift. b) with Stokes drift. C) shows the mean directional wave spectra from SWAN model output in the SnailDel domain over the 30 day release period (direction is the direction waves come from). Particle initial locations are designated by the dark grey circle. In this example more particles enter the bay when stokes drift is included than when it is omitted, consistent with waves entering the domain from the southwest.

\section{New feature summary}

OTP models are a useful tool for investigating a wide range of physical, chemical and biological processes in the world's oceans. As such, these models are continuously improved. Here we introduced updates to a widely used and successful OTP model (LTRANS), which we release under the name of ROMSPath. The base coordinate system used for advection in ROMSPath is now ROMS' $\xi, \eta$ coordinates, improving accuracy and efficiency. ROMSPath also has the flexibility to use output from multiple ROMS nested grids, enabling particle tracking across grid resolutions at execution time. A correction to the vertical mixing parameterization help to reduce clustering in regions where diffusivity gradients are large, while the ability to split the advective and diffusive time step increases numerical efficiency to make the use of appropriate time steps more practical. Finally, functionality for the addition of Stokes and/or behavioural velocities to the hydrodynamic velocity output from ROMS is included.

\section{Code Availability}

The source code for ROMSPath is hosted on GitHub at https://github.com/imcslatte/ROMSPath/tree/V1.0.0. The associated Zenodo DOI is https://doi.org/10.5281/zenodo.5597732 (E. J. Hunter, 2021).

\section{Author contributions}

415 EH is the primary code developer for ROMSPath. JW's expertise in model development and ROMS led to several of the major updates described here. HF, GG, and RC were the principal investigators for the project and provided valuable suggestions for improvements to ROMSPath and the manuscript preparation. JC and HF were the first users of ROMSPath, giving feedback on ROMSPath usability and insight during manuscript preparation.

\section{Competing interests}

420 The authors declare that they have no conflict of interest. 
https://doi.org/10.5194/gmd-2021-400

Preprint. Discussion started: 20 December 2021

(C) Author(s) 2021. CC BY 4.0 License.

(c) (i)

\section{Acknowledgments}

We thank Elizabeth North and Zachary Schhlag for their work on LTRANS, providing a solid foundation for ROMSPath development. The Doppio model configuration was developed by Julia Levin and Alex Lopez. Julia Levin further provided the Doppio reanalysis dataset. This material is based upon work supported by the National Science Foundation NSF Grants OCE-1756646 to HLF and RJC, and OCE-1756591 and OCE- 2051795 to GPG.

\section{Financial support}

This material is based upon work supported by the National Science Foundation NSF Grants OCE-1756646 to HLF and RJC, and OCE-1756591 and OCE- 2051795 to GPG.

\section{References}

Banas, N. S., McDonald, P. S., \& Armstrong, D. A. (2009). Green Crab Larval Retention in Willapa Bay, Washington: An Intensive Lagrangian Modeling Approach. Estuaries and Coasts, 32(5), 893-905. doi:10.1007/s12237-009-9175-7

Beegle-Krause, J. (2001). General Noaa Oil Modeling Environment (Gnome): A New Spill Trajectory Model. International Oil Spill Conference Proceedings, 2001(2), 865-871. doi:10.7901/2169-3358-2001-2-865

Beron-Vera, F. J., \& LaCasce, J. H. (2016). Statistics of Simulated and Observed Pair Separations in the Gulf of Mexico. Journal of Physical Oceanography, 46(7), 2183-2199. doi:10.1175/JPO-D-15-0127.1

Booij, N., Ris, R. C., \& Holthuijsen, L. H. (1999). A third-generation wave model for coastal regions: 1. Model description and validation. Journal of Geophysical Research: Oceans, 104(C4), 7649-7666. doi:10.1029/98jc02622

Chu, P. C., Ivanov, L. M., Kantha, L. H., Margolina, T. M., Melnichenko, O. V., \& Poberezhny, Y. A. (2004). Lagrangian predictability of high-resolution regional models: the special case of the Gulf of Mexico. Nonlinear Processes in Geophysics, 11(1), 47-66. doi:10.5194/npg-11-47-2004

Dagestad, K.-F., Röhrs, J., Breivik, Ø., \& Ådlandsvik, B. (2018). OpenDrift v1.0: a generic framework for trajectory modelling. Geoscientific Model Development, 11(4), 1405-1420. doi:10.5194/gmd-11-1405-2018

Döös, K., Jönsson, B., \& Kjellsson, J. (2017). Evaluation of oceanic and atmospheric trajectory schemes in the TRACMASS trajectory model v6.0. Geoscientific Model Development, 10(4), 1733-1749. doi:10.5194/gmd-10-1733-2017

Drévillon, M., Bourdallé-Badie, R., Derval, C., Lellouche, J. M., Rémy, E., Tranchant, B., . . Parent, L. (2014). The GODAE/MercatorOcean global ocean forecasting system: results, applications and prospects. Journal of Operational Oceanography, 1(1), 51-57. doi:10.1080/1755876x.2008.11020095

Egbert, G. D., \& Erofeeva, S. Y. (2002). Efficient Inverse Modeling of Barotropic Ocean Tides. Journal of Atmospheric and Oceanic Technology, 19(2), 183-204. doi:10.1175/1520-0426(2002)019<0183:Eimobo>2.0.Co;2

Feng, M., Caputi, N., Penn, J., Slawinski, D., de Lestang, S., Weller, E., . . . Brickman, D. (2011). Ocean circulation, Stokes drift, and connectivity of western rock lobster (Panulirus cygnus) population. Canadian Journal of Fisheries and Aquatic Sciences, 68(7), 1182-1196. doi:10.1139/f2011-065

Garvine, R. W. (1991). Subtidal frequency estuary-shelf interaction: Observations near Delaware Bay. Journal of Geophysical Research, 96(C4). doi:10.1029/91jc00079 
https://doi.org/10.5194/gmd-2021-400

Preprint. Discussion started: 20 December 2021

(c) Author(s) 2021. CC BY 4.0 License.

Gerbi, G. P., Kastner, S. E., \& Brett, G. (2015). The Role of Whitecapping in Thickening the Ocean Surface Boundary Layer. Journal of Physical Oceanography, 45(8), 2006-2024. doi:10.1175/JPO-D-14-0234.1

Haidvogel, D. B., Arango, H. G., Hedstrom, K., Beckmann, A., Malanotte-Rizzoli, P., \& Shchepetkin, A. F. (2000). Model evaluation experiments in the North Atlantic Basin: simulations in nonlinear terrain-following coordinates. Dynamics of Atmospheres and Oceans, 32(3-4), 239-281. doi:10.1016/s0377-0265(00)00049-x

Hunter, E. J. (2021). ROMSPath v1.0: Offline Particle Tracking for the Regional Ocean Modeling System (ROMS). In. https://doi.org/10.5281/zenodo.4457931.

Hunter, J. R., Craig, P. D., \& Phillips, H. E. (1993). On the use of random walk models with spatially variable diffusivity. Journal of Computational Physics, 106(2), 366-376. doi:10.1016/s0021-9991(83)71114-9

Janjic, Z., Black, T., Pyle, M., Rogers, E., Chuang, H. Y., DiMego, G. (2005). High resolution applications of the WRF NMM. 21st Conference onWeather Analysis and Forecasting/17th Conference on Numerical Weather Prediction, Washington, DC,.

Lange, M., \& van Sebille, E. (2017). Parcels v0.9: prototyping a Lagrangian ocean analysis framework for the petascale age. Geoscientific Model Development, 10(11), 4175-4186. doi:10.5194/gmd-10-4175-2017

Lellouche, J.-M., Greiner, E., Le Galloudec, O., Garric, G., Regnier, C., Drevillon, M., . . Le Traon, P.-Y. (2018). Recent updates to the Copernicus Marine Service global ocean monitoring and forecasting real-time $1 / 12^{\circ}$ high-resolution system. Ocean Science, 14(5), 1093-1126. doi:10.5194/os-14-1093-2018

Lett, C., Verley, P., Mullon, C., Parada, C., Brochier, T., Penven, P., \& Blanke, B. (2008). A Lagrangian tool for modelling ichthyoplankton dynamics. Environmental Modelling \& Software, 23(9), 1210-1214. doi:10.1016/j.envsoft.2008.02.005

Levin, J., Arango, H. G., Laughlin, B., Wilkin, J., \& Moore, A. M. (2019). The impact of remote sensing observations on cross-shelf transport estimates from 4D-Var analyses of the Mid-Atlantic Bight. Advances in Space Research. doi:10.1016/j.asr.2019.09.012

Liubartseva, S., Coppini, G., Lecci, R., \& Clementi, E. (2018). Tracking plastics in the Mediterranean: 2D Lagrangian model. Mar Pollut Bull, 129(1), 151-162. doi:10.1016/j.marpolbul.2018.02.019

López, A. G., Wilkin, J. L., \& Levin, J. C. (2020). Doppio - a ROMS (v3.6)-based circulation model for the Mid-Atlantic Bight and Gulf of Maine: configuration and comparison to integrated coastal observing network observations. Geoscientific Model Development, 13(8), 3709-3729. doi:10.5194/gmd-13-3709-2020

Mellor, G. L., \& Yamada, T. (1982). Development of a turbulence closure model for geophysical fluid problems. Reviews of Geophysics, 20(4), 851. doi:10.1029/RG020i004p00851

Mesinger, F., DiMego, G., Kalnay, E., Mitchell, K., Shafran, P. C., Ebisuzaki, W., . . Shi, W. (2006). North American Regional Reanalysis. Bulletin of the American Meteorological Society, 87(3), 343-360. doi:10.1175/bams-87-3-343

Monismith, S. G., \& Fong, D. A. (2004). A note on the potential transport of scalars and organisms by surface waves. Limnology and Oceanography, 49(4), 1214-1217. doi:10.4319/lo.2004.49.4.1214

North, E., Schlag, Z., Hood, R., Li, M., Zhong, L., Gross, T., \& Kennedy, V. (2008). Vertical swimming behavior influences the dispersal of simulated oyster larvae in a coupled particle-tracking and hydrodynamic model of Chesapeake Bay. Marine Ecology Progress Series, 359, 99-115. doi:10.3354/meps07317

Phillips, O. M. (1966). The Dynamics of the Upper Ocean: Cambridge University Press.

Ris, R. C., Holthuijsen, L. H., \& Booij, N. (1999). A third-generation wave model for coastal regions: 2. Verification. Journal of Geophysical Research: Oceans, 104(C4), 7667-7681. doi:10.1029/1998jc900123

Röhrs, J., Christensen, K. H., Hole, L. R., Broström, G., Drivdal, M., \& Sundby, S. (2012). Observation-based evaluation of surface wave effects on currents and trajectory forecasts. Ocean Dynamics, 62(10-12), 1519-1533. doi:10.1007/s10236-012-0576-y

Rypina, I. I., Pratt, L. J., Pullen, J., Levin, J., \& Gordon, A. L. (2010). Chaotic Advection in an Archipelago*. Journal of Physical Oceanography, 40(9), 1988-2006. doi:10.1175/2010JPO4336.1

Schlag, Z. R., \& North, E. W. (2012). Lagrangian TRANSport model (LTRANS v.2) User’s Guide. In (pp. 146 pp): University of Maryland Center for Environmental Science, Horn Point Laboratory. Cambridge, MD.

Shadden, S. C., Lekien, F., \& Marsden, J. E. (2005). Definition and properties of Lagrangian coherent structures from finite-time Lyapunov exponents in two-dimensional aperiodic flows. Physica D: Nonlinear Phenomena, 212(3-4), 271-304. doi:10.1016/j.physd.2005.10.007

Shchepetkin, A. F., \& McWilliams, J. C. (2005). The regional oceanic modeling system (ROMS): a split-explicit, free-surface, topographyfollowing-coordinate oceanic model. Ocean Modelling, 9(4), 347-404. doi:10.1016/j.ocemod.2004.08.002

Thomson, J., Schwendeman, M. S., Zippel, S. F., Moghimi, S., Gemmrich, J., \& Rogers, W. E. (2016). Wave-Breaking Turbulence in the Ocean Surface Layer. Journal of Physical Oceanography, 46(6), 1857-1870. doi:10.1175/jpo-d-15-0130.1

Tolman, H. L. (2002). User manual and system documentation of WAVEWATCH-III version 2.22. . NOAA / NWS / NCEP / OMB technical note 222.

Umlauf, L., \& Burchard, H. (2003). A generic length-scale equation for geophysical turbulence models. Journal of Marine Research, 61(2), 235-265. doi:10.1357/002224003322005087

van Sebille, E., Griffies, S. M., Abernathey, R., Adams, T. P., Berloff, P., Biastoch, A., . . Zika, J. D. (2018). Lagrangian ocean analysis: Fundamentals and practices. Ocean Modelling, 121, 49-75. doi:10.1016/j.ocemod.2017.11.008 
https://doi.org/10.5194/gmd-2021-400

Preprint. Discussion started: 20 December 2021

(c) Author(s) 2021. CC BY 4.0 License.

515 Vennell, R., Scheel, M., Weppe, S., Knight, B., \& Smeaton, M. (2021). Fast lagrangian particle tracking in unstructured ocean model grids. Ocean Dynamics, 71(4), 423-437. doi:10.1007/s10236-020-01436-7

Visser, A. (1997). Using random walk models to simulate the vertical distribution of particles in a turbulent water column. Marine Ecology Progress Series, 158, 275-281. doi:10.3354/meps158275

Warner, J. C., Defne, Z., Haas, K., \& Arango, H. G. (2013). A wetting and drying scheme for ROMS. Computers \& Geosciences, 58, 5461. doi:10.1016/j.cageo.2013.05.004

Wilkin, J., Levin, J., Lopez, A., Hunter, E., Zavala-Garay, J., \& Arango, H. (2018). A Coastal Ocean Forecast System for U.S. Mid-Atlantic Bight and Gulf of Maine. In New Frontiers in Operational Oceanography.

Xue, H., Incze, L., Xu, D., Wolff, N., \& Pettigrew, N. (2008). Connectivity of lobster populations in the coastal Gulf of Maine. Ecological Modelling, 210(1-2), 193-211. doi:10.1016/j.ecolmodel.2007.07.024

525 Yeung, P. K. (2002). Lagrangian investigations of turbulence. Annual Review of Fluid Mechanics, 34(1), 115-142. doi:10.1146/annurev.fluid.34.082101.170725 